\title{
Exopolysaccharides from Lactobacillus plantarum YW11 improve immune response and ameliorate inflammatory bowel disease symptoms
}

\author{
Zhang Min, Hao Xiaona, Tariq Aziz, Zhang Jian and Yang Zhennai® \\ Beijing Advanced Innovation Center for Food Nutrition and Human Health, Beijing Technology and Business University, Beijing, China
}

Exopolysaccharides (EPSs) possess many bioactivities such as immune regulation, antioxidant, anti-tumor and modulation of intestinal microbial balance but their direct effect on inflammatory bowel disease (IBD) response has not been studied. The purpose of this study was to evaluate the anti-inflammatory effect of EPS produced by L. plantarum YW11 administered at different dosages in IBD mouse model induced with $5 \%$ dextran sulphate sodium (DSS). The DSS-induced colitis, accompanied by body weight loss, reduction of colon coefficient and histological colon injury was considerably ameliorated in mice fed the EPS $(10 \mathrm{mg} / \mathrm{kg})$. The middle dose of the EPS (25 mg/kg) could effectively recover the intestinal microbial diversity and increase the abundance of Roseburia, Ruminococcus and Blautia with increased content of butyric acid. Moreover, EPS also reduced the production of pro-inflammatory cytokines (TNF- $\alpha$, IL-1 $\beta$, IL-6, IFN- $\gamma$, IL-12 and IL-18) and enhanced the anti-inflammatory cytokine IL-10. This study showed that EPS might help in modulation of gut microbiota and improve the immunity of the host to reduce the risk of IBD symptoms.

Key words: Exopolysaccharide (EPS); Lactobacillus plantarum; Inflammatory bowel disease; Gut microbiota; Immunity

Received: 21 January, 2020; revised: 05 June, 2020; accepted: 10 September, 2020; available on-line: 17 December, 2020

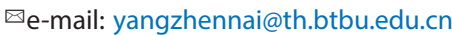

Acknowledgements of Finanacial Support: This study was financially supported by National Natural Science Foundation of China (No. 31871823), National Key Research and Development Program of China (2018YFC1604302), and Beijing Talent Cultivation Quality Construction - First-class Professional Construction (Municipal Level) - Food Science and Engineering (PXM2019 014213 000010). Abbreviations: CD, Crohn's Disease; DSS, Dextran Sulphate Sodium; EPSs, Exopolysaccharides; GC-MS, Gas Chromatography and Mass Spectrometry; IBD, Inflammatory Bowel Disease; LAB, Lactic Acid Bacteria; RDA, Redundancy Analysis; SCFAs, Short Chain Fatty Acids; SIM, Single Ion Monitor; UC, Ulcerative Colitis

\section{INTRODUCTION}

Inflammatory bowel disease (IBD), including ulcerative colitis (UC) and Crohn's disease (CD), is a common chronic intestinal disease caused by a diversity of complex factors such as genetic, environmental, intestinal, and immune ones (Kong et al., 2008; Dudik et al., 2018). Intestinal flora and mucosal immune disorders play an important role in the pathogenesis of IBD (Dasgupta et al., 2013, Bringiotti et al., 2014). Hansen found that the diversity of intestinal flora of IBD patients was reduced significantly (Hansen et al., 2010) and the number of bacterial genes in feces of the patients was lower by $25 \%$ when compared with those of healthy people (Qin et al.,
2010). It was shown that the intestinal microbiota balance in IBD patients was broken with reduced number of beneficial bifidobacterium and increased sulfate reducing bacteria, as well as decreased formation of butyrate in gut and increased intestinal permeability, allowing bacterial endotoxin pro- inflammatory substances to enter the intestinal mucosa lamina propria to induce immune inflammatory reaction. Sokol and others (Sokol et al., 2008) reported that the number of anti-inflammatory Clostridium Difficile in the intestinal mucosa of patients with CD also decreased significantly. In the treatment of IBD, probiotic Lactobacillus casei Lbs2 was shown to induce differentiation of regulatory $\mathrm{T}$ cells (Tregs) to secrete higher level of IL-10 that exerted therapeutic effect on IBD and then IL-10 inhibited the releasing of the proinflammatory factors such as IL-1, IL-6, IL-12 and TNF (Smith et al., 2013; Thakur et al., 2016). Regulation of the intestinal flora to maintain its balance and enhancement of intestinal mucosal immunity were considered vital for treatment of IBD, e.g. by using probiotics or prebiotic preparations (Guarner et al., 2007; Sun et al., 2018).

Prebiotics are generally a kind of indigestible dietary supplements which are useful to stimulate the growth and activity of bacteria, especially they can inhibit the growth of intestinal pathogens, thus conferring beneficious health effect on the host (Gibson et al., 2004). Exopolysaccharides (EPSs) are produced by lactic acid bacteria (LAB), biologically serving as a natural protective barrier to safeguard the bacteria from the adverse environment (Ramchandran et al., 2009), EPSs were reported to possess prebiotic function with various physiological properties, such as anti-oxidation, anti-tumor, and cholesterol lowering (Vuyst et al., 2001). Das and others (Das et al., 2014) proved that the EPS produced by L. plantarum DM5 had bifidogenic effect. Peptidoglycan, polysaccharide fragments and glycoproteins from Bifidobacterium adolescentis SPM0212 had anti-tumor effect (Arun et al., 2014). The EPS produced by B. lactis Bb12 promoted proliferation of $\mathrm{T}$ lymphocytes (Amrouche et al., 2006). The EPS synthesized by L. paracasei KB28 promoted secretion of immune factors IL-6, IL-12 and TNF- $\alpha$ (Amrouche et al., 2006). By using the acetic acid induced colitis mouse model, L. delbrueckii subsp. bulgaricus B3 producing higher amount of EPS was found to significantly reduce inflammation in mice when compared to L. delbrueckii subsp. bulgaricus A13 with low EPS production and the former also showed to have higher antioxidant activity and metal chelating ability than latter. Currently, the EPS produced by L. plantarum YW11 was reported to relieve oxidative stress of the galactoseinduced aging mice by regulating the gastrointestinal microbiota balance (Jian et al., 2017), but the direct evi- 
dence on the curative effect of the EPSs produced by $\mathrm{LAB}$ on IBD has not been reported.

For the treatment of IBD, probiotics, such as lactobacilli and bifidobacteria, were extensively studied for their regulating effects on gut microbiota, and there was a certain causal relationship between intestinal flora and IBD (Dong et al., 2019). The EPS-producing probiotic strains were shown to alleviate the gut oxidative damage in experimental colitis (Sengul et al., 2011b), Although EPSs produced by LAB were reported with different bioactivities, there was no direct evidence on their curative effects on IBD. Previously in our lab, we found that the EPS produced by L. plantarum YW11 possessed the function of regulating intestinal flora to relieve the oxidative stress of a mouse model (Jian et al., 2017). In this study, the EPS produced by YW11 was further shown to be effective to alleviate the IBD related symptoms by recovering the microbial diversity and improving the immune response of the IBD mice.

After the experimental mice were modeled by DSS, they gradually lost body weight when compared to the healthy mice without DSS treatment, probably due to reduced diet and water intake of the model mice as reported earlier (Morhardt et al., 2019). Administration of the EPS produced by L. plantarum YW11 increased the weight gain compared to the negative group, and improved the symptoms of the colon inflammation, indicating that the EPS had a certain effect on the recovery of gastroenteritis in mice. Similarly, Kim showed that the Portulaca oleracea extracts probably containing its secreted polysaccharides ameliorated IBD in vivo, and the weight of the mice treated with the Portulaca oleracea extracts increased (Kim et al., 2018). It was also observed that the ratio of colon weight to body weight significantly increased in the DSS groups, accompanying with different degrees of hyperemia, edema, and thickening of the inflammatory response in the colon, and the corresponding $\mathrm{HE}$ scores were higher as reported previously (Mueller et al., 2009). In the preventive approach, the animals treated with the EPS from L. plantarum YW11 showed less edema and neutrophil infiltration, as well as a restoration of the mucosa, submucosa and muscular layers. Comparatively, the EPSproducing $B$. adolescentis IF1-03 was also reported to reduce the area of ulceration and thickening of the intestinal wall compared to the DSS-colitis model mice (Yu et al., 2019), but whether this EPS played the roles or not was not confirmed.

In this study, the effect of the EPS produced by $L$. plantarum YW11 on the dextran sulfate sodium (DSS) induced IBD mice colitis model was studied, focusing on the regulatory effect of the EPS on the gut microbiota composition and the immune response. The EPS was previously characterized with a molecular mass of $1.1 \times 10^{5} \mathrm{Da}$, with the monosaccharide composition of glucose and galactose in a molar ratio of 2.71:1 (Wang et al., 2018). The present study will provide further understanding of the prebiotic function and mechanism of the EPSs produced by L. plantarum in the treatment of intestinal inflammatory diseases.

The EPS produced by L. plantarum YW11 exerted its curative effect on IBD by simulating expression of the anti-inflammatory cytokine IL-10, and decreasing levels of the pro inflammatory TNF- $\alpha$, IL- $1 \beta$, IL-6, IFN- $\gamma$, IL-12 and IL-18 in the colon tissue of the DSS mice. IL-10 could increase expression of anti-inflammatory proteins such as soluble $\mathrm{TNF}-\alpha$ receptor and matrix metalloproteinase tissue inhibitors, which protected the intestinal epithelial barrier (Staples et al., 2000). IL-1 $\beta$ could promote the macrophages and monocytes to secrete TNF- $\alpha$ and IL-6 in an autocrine and paracrine mode, leading to inflammation that damaged intestinal epithelial barrier function and caused further deterioration of IBD (Ishiguro et al., 1999). Synergistic effect of IL-12 and IL-18 promoted secretion of large amounts of IFN- $\gamma$ by NK and Th1/Th2 cells and played a proinflammatory role (Nakanishi et al., 2003). Previously the bacterial $\beta$-(1,3)-glucan was found to exert its antiinflammatory effect by promoting gene expression of IL-10 in DSS-induced colitis mice (Lee et al., 2014). Other polysaccharides inhibited expression of the pro inflammatory factors such as IL-1 $\beta$, IL-6, TNF- $\alpha$ in IBD tissues (Pereira et al., 2016). Lactulose had immunomodulatory effect on TNBS-induced colitis rats by decreasing the content of $\mathrm{TNF}-\alpha$, thus reducing epithelial cell injury and intestinal mucosa ulcer (Yan et al., 2015). Portulaca oleracea inhibited IBD by controlling the levels of the inflammatory cytokines TNF- $\alpha$, IL-6 and IL-1 $\beta$ in mice with DSS-induced IBD (Kim et al., 2018).

Short-chain fatty acids (SCFAs) produced by gut microbial fermentation with polysaccharides were considered to be beneficial in maintaining a relatively low $\mathrm{pH}$ value of colon and preventing the growth of potentially harmful bacteria. The SCFAs produced by probiotic Clostridium difficile could induce differentiation of primary CD4+ $\mathrm{T}$ cells into regulatory $\mathrm{T}$ cells (Treg), which stimulated secretion of IL-10 by macrophages, thereby reducing the inflammatory response (Bhat et al.,. 2019). In this study, the contents of SCFAs were different in the 6 experimental groups with butyric acid to be the highest, possibly because most of the butyric acid producing colonies existed in the intestinal flora. The experimental statistics of the butyric acid producing colonies found that Roseburia increased by $0.39 \%$, Ruminococcus increased by $0.08 \%$ and Blautia increased by $0.56 \%$. Butyrate could be the main energy source for colonic epithelial cells, and it inhibited the immune inflammatory response and the downstream pro-inflammatory IL-12, and up-regulated the production of anti-inflammatory cytokine IL-10 (Backhed et al.,. 2007). This might also be a mechanism of alleviating the inflammatory response of IBD by the EPS from L. plantarum YW11.

Previous studies showed that decrease of intestinal flora diversity was closely related to the generation of IBD inflammation (Gevers et al., 2014). Complex carbohydrates could increase levels of beneficial bacteria bifidobacterial and regulate intestinal microenvironment, stimulating macrophages and lymphocytes in the gut, and fighting inflammatory diseases (Gevers et al., 2014). In this study, treatment of the IBD mice with the EPS from L. plantarum YW11 increased the richness of intestinal flora, indicating that the EPS could alleviate symptoms of IBD inflammation by increasing the diversity of intestinal flora. As indicated by correlation analysis between intestinal flora and cytokines, the relative abundance of beneficial Lactobacillus and Bacteroidales-S24-7 was significantly positively correlated with IL-10 anti-inflammatory cytokines. The relative abundance of Lachnospiraceae, Faecalibaculum, Fissicatena, Escherichia, Shigella and Streptococcus was positively correlated with TNF- $\alpha$, IL- $1 \beta$, IL- 6 , IFN- $\gamma$, IL-12 and IL-18 pro-inflammatory cytokines. The results of this study regarding the relationship among the SCFAs, cytokines and intestinal flora suggested that the 
mechanism of the effective treatment with the LAB EPSs for IBD was gaining new understanding.

\section{MATERIAL AND METHODS}

Strains and culture condition. L. plantarum YW11 isolated from Tibetan kefir maintained in the culture bank of Dairy Laboratory in Beijing Technology and Business University of China at $-80^{\circ} \mathrm{C}$ was activated by consecutive transfer for three times in MRS medium (Beijing Aoboxing Co Ltd) at $37^{\circ} \mathrm{C}$ for $18 \mathrm{hr}$. Skim milk medium made by reconstituting $10 \%$ skim milk powder (Fonterra, Auckland, New Zealand) in deionized water was used for growth of the strain for preparing the EPS sample used in this study (Wang et al., 2018).

Preparation of EPS. The EPS produced by L. plantarum YW11 was isolated and purified by the following method as described (Wang et al., 2015). Briefly, the skim milk medium (1 L) was inoculated with $L$. plantarum YW11 at $3 \%(\mathrm{v} / \mathrm{v})$. After growth at $37^{\circ} \mathrm{C}$ for $18 \mathrm{hr}$, the culture was heated in a boiling water bath for $15 \mathrm{~min}$ to inactivate possible polysaccharide-degrading enzymes. Then trichloroacetic acid (TCA) at $80 \%(\mathrm{w} / \mathrm{v})$ was added to the final concentration of $4 \%(\mathrm{w} / \mathrm{v})$. The mixture was stirred at room temperature for $2 \mathrm{hr}$, and then centrifuged at $10000 \mathrm{rpm}$ at $4^{\circ} \mathrm{C}$ for $45 \mathrm{~min}$. The supernatant was added with two volumes of cold ethanol $\left(4^{\circ} \mathrm{C}\right)$, kept at $4^{\circ} \mathrm{C}$ for $12 \mathrm{hr}$, and centrifuged at 10000 $\mathrm{rpm}$ at $4^{\circ} \mathrm{C}$ for $30 \mathrm{~min}$. The precipitate was dissolved with distilled water, dialyzed for $48 \mathrm{hr}$ with a molecular cutoff of 8000-14000 Da, and then lyophilized to obtain the crude EPS. Purification of the EPS sample $(20 \mathrm{mg} /$ $\mathrm{mL}$ distilled $\mathrm{H}_{2} \mathrm{O}$ ) was performed with a diethylaminoethyl cellulose column (GE Healthcare, Pittsburgh, PA), and subsequently with a Sepharose CL-6B column (GE Healthcare, Pittsburgh, PA). Peak fractions containing the EPS were collected and lyophilized to obtain the purified EPS sample, which was stored at $-20^{\circ} \mathrm{C}$ for further use.

Animal experiments. Male ICR mice weighing 18$22 \mathrm{~g}$ were used for the experiments. Mice were housed in sawdust-lined plastic cages at a constant temperature $\left(22-24^{\circ} \mathrm{C}\right)$ and maintained under a $12 \mathrm{hr}$ light/dark cycle (lights on at 6:00 a.m.) with free access to laboratory chow and water. The animals were maintained under the conditions and used for the experiment after 7 days of acclimation. Groups of 6-8 animals were used in the experiments. The animal experiments conducted strictly according to the Provisions and General Recommendations of Chinese Experimental Animal Administration Legislation.

Mice ( $n=48$ ) were randomized into the following six groups: the blank (B) group consisted of healthy animals; the negative $(\mathrm{N})$ group was administered with $5 \%$ DSS (M.W. 36000-50000, MP Biomedicals, LLC, France) to induce bowel inflammation and then treated with $0.9 \%$ normal saline at a dose of $20 \mathrm{~mL} / \mathrm{kg}$ (body weight) per day; the positive (P) group was administered with $5 \%$ DSS to induce bowel inflammation and then treated with prednisolone acetate injection (Hua-Yi-Hu-Bei Pharmaceutical Co., Ltd, China) at a dose of $5.0 \mathrm{mg} /$ $\mathrm{kg}$ per day; the YW11-L group was administered with $5 \%$ DSS to induce bowel inflammation and then treated with the EPS at a low dose of $10.0 \mathrm{mg} / \mathrm{kg}$ per day; the YW11-M group was administered with $5 \%$ DSS to induce bowel inflammation and then treated with the EPS at a medium dose of $25.0 \mathrm{mg} / \mathrm{kg}$ per day; the YW11-H group was administered with 5\% DSS to induce bowel inflammation and then treated with the EPS at a high dose of $50.0 \mathrm{mg} / \mathrm{kg}$ per day.

The animals received DSS solution on days 1-14 to induce bowel inflammation, and in the following week (days 15-21) the animals in different groups received the different treatments as described above. On day 22, all mice were sacrificed and the colon without caecum was immediately removed, measured and weighed. The colon coefficient was calculated as the weight of colon divided by the weight of mouse (Paquola et al., 2019). Then the fecal pellets were removed. Clinical parameters including diarrhea were observed daily, and animal body weight was assessed.

Histology evaluation. The colon was fixed using $4 \%$ paraformaldehyde and embedded in paraffin. Fivemicrometer-thick sections were sliced from the paraffin block and stained with hematoxylin and eosin (H\&E). Histological scoring was performed on H\&E-stained colon tissue sections; the degree of involvement was graded on a scale of $1-4(1,0-25 \% ; 2,26-50 \% ; 3,51-75 \%$; $4,76-100 \%$ ), and the extent of injury on a scale of $0-4$ (0, negative; 1, mucosal; 2, submucosa; 3, muscularis mucosal; 4 , serosa regions). Two scores per mouse were added for the total score of the individual animal. The average scores for each group were calculated (Horino et al., 2008).

Cytokine analysis. Local levels of IL-1 $\beta$, IL-18, IL-6, IL-12, TNF- $\alpha$, IFN- $\gamma$, IL-10 were assessed according to the instructions of the ELISA kit (Hua-Mei-Wu-Han Pharmaceutical Co., Ltd-China). Sample preparation: Precooled cracking fluid was added to colonic tissue, grinded, and centrifuged (12000 rpm, $\left.4^{\circ} \mathrm{C}, 10 \mathrm{~min}\right)$. Then the protein concentration of the supernatant was determined.

Assay procedure: $100 \mu \mathrm{l}$ of sample was added to each well and incubated for $2 \mathrm{hr}$ at $37^{\circ} \mathrm{C}$. The liquid in each well was removed without washing. $100 \mu \mathrm{l}$ of biotinantibody $(1 \mathrm{X})$ was then added to each well, incubated for $1 \mathrm{hr}$ at $37^{\circ} \mathrm{C}$, aspirated and washed 3 times. $100 \mu \mathrm{l}$ of HRP-avidin (1X) was added to each well, incubated for $1 \mathrm{hr}$ at $37^{\circ} \mathrm{C}$, aspirated and washed 5 times. $90 \mu \mathrm{l}$ of TMB substrate was added to each well and incubated for 15-30 minutes at $37^{\circ} \mathrm{C}$ under dark conditions. $50 \mu \mathrm{l}$ of Stop Solution was added to each well, and optical density was determined at $450 \mathrm{~nm}$ within 5 minutes.

Determination of short chain fatty acids (SCFAs) in feces. The SCFAs in feces were determined using a method described by (Shixiang et al., 2018). Briefly, feces were collected from individual mouse. Fecal samples (50 mg) were added to $2 \mathrm{ml}$ water, acidified with sulfuric acid $(10 \%)$ to adjust the $\mathrm{pH}$ to $2-3$, and resuspended by shaking for $2 \mathrm{~min}$. Then, $1 \mathrm{ml}$ diethyl ether was added; $10 \mathrm{~min}$ later, the sample was centrifuged at $1800 \mathrm{rpm}$ for $10 \mathrm{~min}$ to remove the solid material. Supernatants were retained, 2-methyl-3-heptanone solution in ether was added as internal standard, and the solution was filtered through a $0.45 \mu \mathrm{m}$ microporous membrane. Samples were analyzed by GC-MS within 24 h. $1 \mu \mathrm{L}$ of sample was injected into GC-MS, which was equipped with a DB-Wax column. Helium was the carrier gas at a flow rate of $0.8 \mathrm{~mL} / \mathrm{min}$. The injection temperature was $180^{\circ} \mathrm{C}$ and the $\mathrm{GC}$ temperature program was as follows: beginning at $60^{\circ} \mathrm{C}$, increasing to $160^{\circ} \mathrm{C}$ at $5^{\circ} \mathrm{C} / \mathrm{min}$, then holding at $160^{\circ} \mathrm{C}$ for $6 \mathrm{~min}$. The ion source temperature was $200^{\circ} \mathrm{C}$. Concentration of SCFAs was analyzed using Single Ion Monitor (SIM) scan mode, calculated using the internal standard method and expressed in $\mu \mathrm{g} / \mathrm{g}$ sample. 

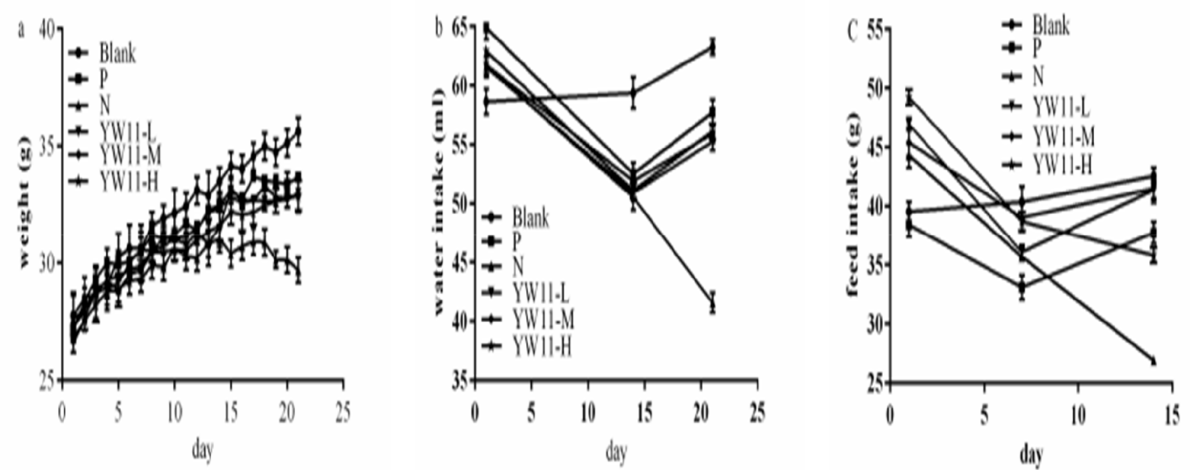

Figure 1.

(a) shows changes of body weights of the mice during the 3 weeks of experimental period. (b) and (c) show the changes of water and feed intake of the mice, respectively, during the experimental period

16S RNA analysis. Feces from three mice were randomly selected from each group. 16S rRNA gene analysis was used to examine the diversity of fecal microbiota in the subjects. Using the NEXT flexTM 16S V4 Amplicon-Seq Kit (Bioo Scientific, USA), primers were used to generate amplicons spanning the variable regions 3-4 (V3-V4) of the 16S rRNA gene that were subsequently sequenced on an Illumina MiSeq (Illumina, USA). Data were processed using QIIME software (v1.9.0).

The partial least square-discriminant analysis (PLSDA) plot was generated based on the UniFrac distance matrix and was used to test the similarity among individual subject groupings of intestinal bacteria. A redundancy analysis (RDA) was completed with CANOCO (Microcomputer Power, Ithaca, NY) according to the software manual (Braak et al., 2002). Briefly, species and environmental data were input into CANOCO software. In the method-selection inspection, the lengths of gradient (1.42) in the detrended correspondence analysis was lower than 3.0, suggesting that the method of RDA was more suitable for data analysis than for canonical correspondence analysis. The significance of RDA analysis was used to analyze the relationship between environmental factors and species.

Statistical Analysis. All data were expressed as mean \pm standard deviation (S.D.). Statistically significant differences were determined by one-way ANOVA analysis followed by Tukey's tests in SPSS 13.0 software (SPSS, Inc., USA).

\section{RESULTS AND DISCUSSION}

\section{Change of physical state of mice}

Figure 1a shows changes of body weights of the mice during the 3 weeks of experimental period. All the mice in the 5 groups treated with DSS (N, P, YW11-L, YW11-M, YW11-H) showed obviously slower increase in the body weight than the normal healthy mice without DSS treatment (group B). Starting from day 15, treatment with different doses of EPS (groups YW11-L, YW11-M, YW11-H) sustained the growth of the mice, but the body weights of these mice were still lower than those of the untreated mice (group B) till the last day of the experimental period, while the mice without EPS treatment (group N) showed substantial decrease of body weight. Figure $1 \mathrm{~b}$ and Fig. 1c show the changes of water and feed intake of the mice, respectively, during the experimental period. During the first 2 weeks, treatment of the mice with DSS significantly affected the water and feed intake, but this was obviously improved when the mice were treated with different doses of EPS starting from day 15, compared to the mice without EPS treatment (group N) that continued to decrease in the water and diet intake till the end of the experiment period.

\section{Colon coefficient and histological analysis}

A major hallmark of DSS-induced colitis is leukocyte infiltration into the colon wall resulting in massive tissue damage (Yan et al., 2009). As shown in Fig. 2a, mice in group $\mathrm{N}$ treated only with DSS had the highest colon coefficient, and also the highest histological HE score (Fig. 2b). This was confirmed by the histopathological assessment of H\&E stained tissue sections of the mice in group $\mathrm{N}$ that revealed a massive destruction of the epithelial lining, a shortening or absence of crypts, loss of goblet cells, and excessive leukocyte infiltrates in the mucosa and submucosa (Fig. 2c). Although there was no significant difference in the values of colon coefficient among the other five groups, treatment of the mice with the EPS showed different extent of protective effect on the colonic tissue. As shown in Fig. 2c, the healthy mice (group B) showed obvious crypt and intact epithelium with no inflammation, and treatment with different doses of the EPS improved the shape of colon tissue in different degrees. This was in line with the result of histological HE scoring where mice in groups YW11-L and YW11-M gave significantly lower histological scores than groups N, P and YW11-H, but higher than group B (Fig. 2b).

\section{Change of cytokine levels in colon tissue of mice}

Interleukin (IL)-10 is an anti-inflammatory cytokine that plays an important role in intestinal homoeostasis, while other cytokines such as TNF- $\alpha$, IFN- $\gamma$, IL- $1 \beta$, IL6 , IL-12 and IL-18 are pro inflammatory with well-established pro inflammatory functions in IBD in humans and animal models (Amaral et al., 2016). Treatment of the mice with DSS (group N) significantly $(P<0.05)$ decreased the level of the anti-inflammatory IL-10 in the intestinal tissue, with almost 0.33 -fold lower level of the cytokine than those in the other five groups (Fig. 3a). In contrast, the levels of the pro inflammatory TNF- $\alpha$, IFN- $\gamma$, IL-1 $\beta$, IL-6, IL-12 and IL-18 increased significantly $(P<0.05)$ in the mice treated with DSS (group $N$ ) with 1-6-fold increase compared to those of the healthy mice (group B) (Fig. 3b, 3c, 3d, 3e, 3f, 3g). However, treatment of the mice with different doses of the EPS 
a.

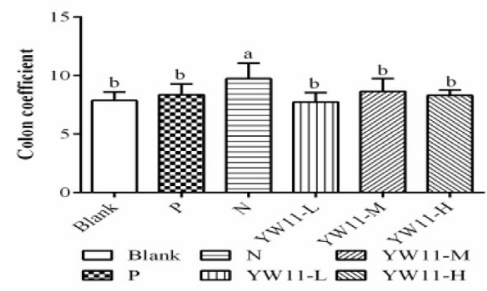

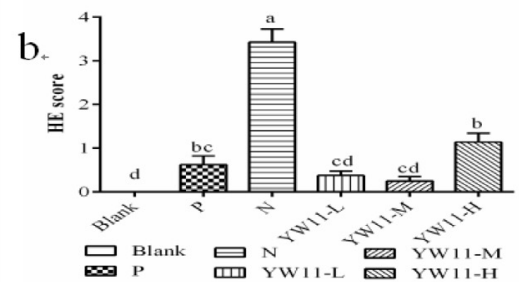

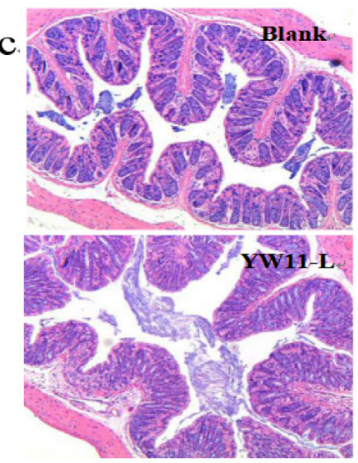

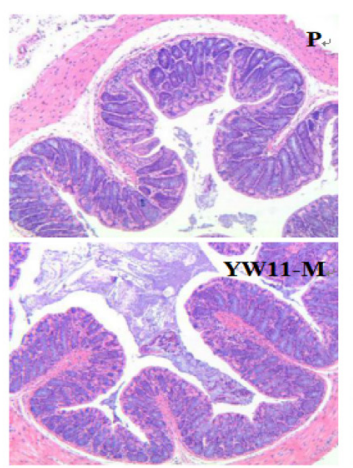

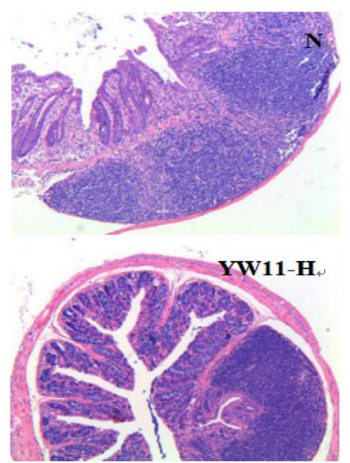

Figure 2. Effect of the EPS produced by L. planarum YW11 on the colon tissue of the IBD mice.

(a) Colon coefficient. (b) Histological score. (c) Representative H\&E-stained colons. Abcd: different letters indicating significant differences at the level $P<0.05$.

significantly $(P<0.05)$ decreased the levels of these six proinflammatory cytokines to different extents, with medium or low dose EPS being more effective than the high dose EPS.

\section{Fecal SCFA concentration of mice}

The SCFAs and their concentrations in feces $(\mu \mathrm{g} / \mathrm{g})$ of mice were determined as shown in Table 1. Comparing with the healthy mice (group B), treatment of the mice with DSS (group N) significantly $(P<0.05)$ decreased the total SCFA concentration, with deceased concentration of formic acid, propanoic acid, isobutyric acid, butyric acid and valeric acid except for acetic acid and isovalic acid. Administration of the EPS at low and medium doses recovered the total SCFA content in feces, especially butyric acid that had the highest concentration among all the SCFAs determined. However, treatment with high-dose EPS decreased the total SCFA concentration in feces with major decrease of butyric acid.

\section{Gut Microbiota Change in mice treated with EPS}

A total of 713465 sequences were obtained after pyrosequencing, and unique sequences were classified and grouped into 402 operational taxonomic units (OTUs) based on $97 \%$ nucleotide sequence identity, and the average length was 443.19. The rarefaction curves (Fig. 4) for all mice reached a plateau, indicating that the bacterial diversity in these communities was mostly covered. The partial least square-discriminant analysis (PLS-DA) of UniFrac distances based on the relative abundance of OTUs revealed the difference in intestinal microbiota at the genus level between the fecal samples from each group (Fig. 5a). The 3 symbols representing the microbial communities from each of the fecal samples from group $\mathrm{N}$ mice were well separated from those of the other five groups, with the distance between the symbols representing the degree of difference of the microbiota, Therefore, the overall microbiota was different in the fecal samples from group $\mathrm{N}$ compared with the other five groups, whereas there was no significant difference between these five groups (B, P, YW11-L, YW11-M and YW11-H). This was further confirmed by microbial community heat map that showed considerable difference in the microbiota composition at genus level between the fecal samples from group $\mathrm{N}$ and those from the other 5 groups (Fig. 5b).

Differences in gut microbial communities before and after EPS administration were also evaluated by $\alpha$-diversity analysis, consisting of richness estimates

Table 1. Content of short-chain fatty acids in feces of mice

\begin{tabular}{lllllll}
\hline Content $(\mu \mathrm{g} / \mathrm{g})$ & Blank & $\mathrm{N}$ & $\mathrm{P}$ & $\mathrm{YW} 11-\mathrm{L}$ & $\mathrm{YW} 11-\mathrm{M}$ & $\mathrm{YW} 11-\mathrm{H}$ \\
\hline acetic acid & $32.40 \pm 8.66^{\mathrm{b}}$ & $33.14 \pm 2.03^{\mathrm{b}}$ & $40.72 \pm 6.06^{\mathrm{b}}$ & $68.95 \pm 9.60^{\mathrm{a}}$ & $22.90 \pm 8.30^{\mathrm{b}}$ & $65.52 \pm 9.31^{\mathrm{a}}$ \\
\hline formic acid & $67.36 \pm 9.97^{\mathrm{ab}}$ & $60.80 \pm 11.67^{\mathrm{ab}}$ & $65.87 \pm 6.23^{\mathrm{a}}$ & $34.20 \pm 3.36^{\mathrm{b}}$ & $38.77 \pm 12.16^{\mathrm{ab}}$ & $51.05 \pm 19.67^{\mathrm{ab}}$ \\
\hline propanoic acid & $60.10 \pm 6.13^{\mathrm{cd}}$ & $53.69 \pm 7.00^{\mathrm{d}}$ & $97.69 \pm 7.50^{\mathrm{a}}$ & $92.86 \pm 8.25^{\mathrm{ab}}$ & $82.06 \pm 8.66^{\mathrm{bc}}$ & $62.70 \pm 7.81^{\mathrm{cd}}$ \\
\hline isobutyric acid & $12.88 \pm 2.86^{\mathrm{a}}$ & $7.73 \pm 2.55^{\mathrm{a}}$ & $11.46 \pm 3.43^{\mathrm{a}}$ & $18.43 \pm 5.67^{\mathrm{a}}$ & $19.34 \pm 11.55^{\mathrm{a}}$ & $16.37 \pm 8.93^{\mathrm{a}}$ \\
\hline butyric acid & $201.29 \pm 12.47 \mathrm{bc}$ & $169.46 \pm 8.49^{\mathrm{c}}$ & $221.97 \pm 6.71^{\mathrm{b}}$ & $313.62^{\mathrm{b}} \pm 14.61^{\mathrm{a}}$ & $264.06 \pm 17.71^{\mathrm{a}}$ & $124.61 \pm 18.46^{\mathrm{d}}$ \\
\hline isovalic acid & $28.82 \pm 7.71^{\mathrm{bc}}$ & $42.51 \pm 7.76^{\mathrm{b}}$ & $64.88 \pm 4.56^{\mathrm{a}}$ & $20.56 \pm 3.23^{\mathrm{c}}$ & $29.16 \pm 7.35^{\mathrm{bc}}$ & $28.16 \pm 6.45^{\mathrm{bc}}$ \\
\hline valeric acid & $25.62 \pm 9.04^{\mathrm{a}}$ & $14.79 \pm 6.38^{\mathrm{ab}}$ & $24.83 \pm 5.67^{\mathrm{a}}$ & $5.82 \pm 1.60^{\mathrm{b}}$ & $5.70 \pm 0.31^{\mathrm{b}}$ & $10.64 \pm 3.32^{\mathrm{b}}$ \\
\hline Total SCFAs & $428.47 \pm 8.12^{\mathrm{c}}$ & $382.13 \pm 6.55^{\mathrm{d}}$ & $527.42 \pm 5.74^{\mathrm{b}}$ & $554.45 \pm 6.62^{\mathrm{a}}$ & $461.99 \pm 9.36^{\mathrm{b}}$ & $359.06 \pm 10.56^{\mathrm{d}}$ \\
\hline
\end{tabular}

abcdstands for different letters indicating significant differences at the level $P<0.05$. 

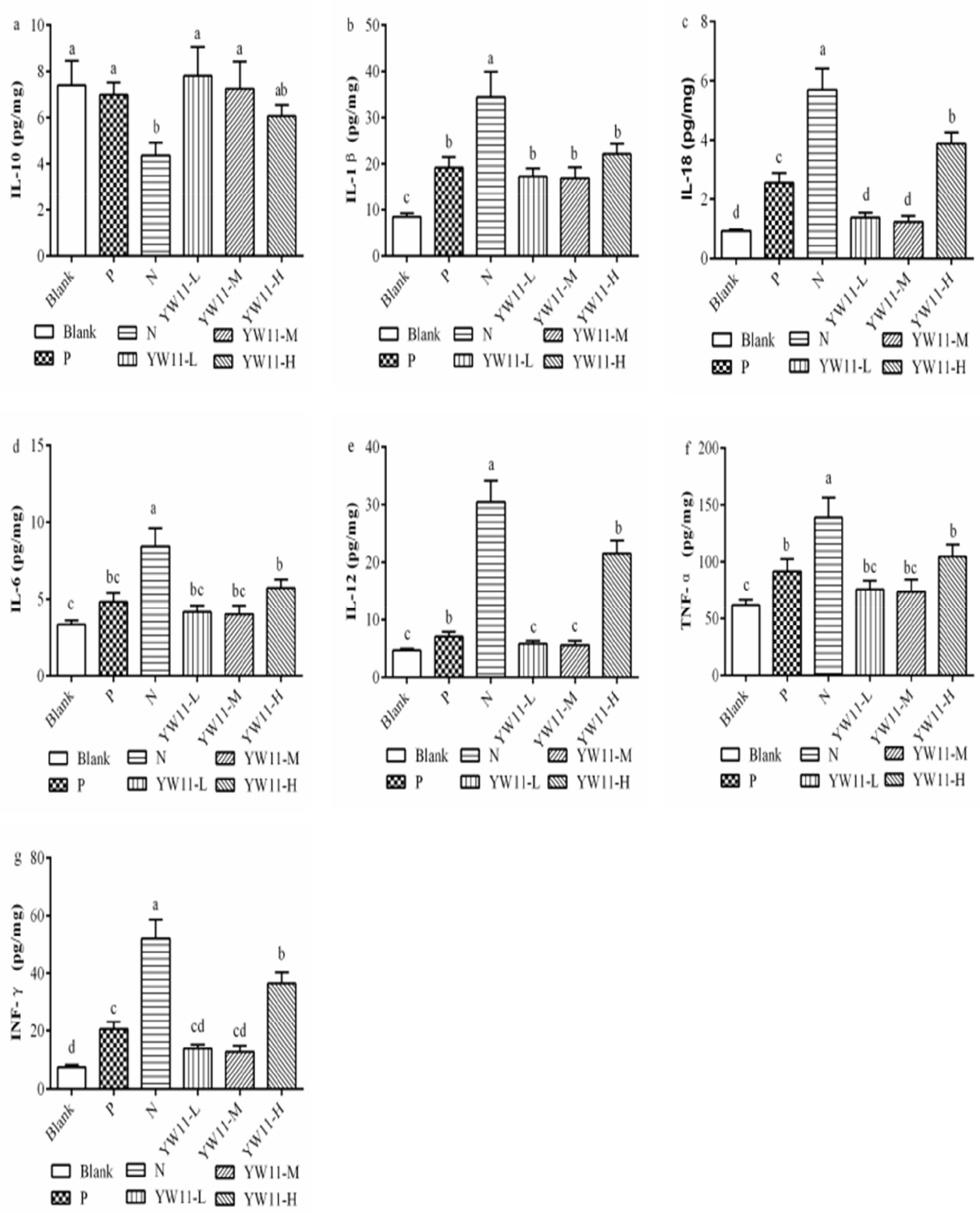

Figure 3. Effect of the EPS produced by L. plantarum YW11 on the cytokine levels of anti-inflammatory IL-10 (a), and proinflammatory IL-1 $\beta$ (b), IL-18 (c), IL-6 (d), IL-12 (e), TNF- $a(f)$ and INF- $\gamma(\mathrm{g})$ in the colon tissue f IBD mice, as determined by ELISAs.
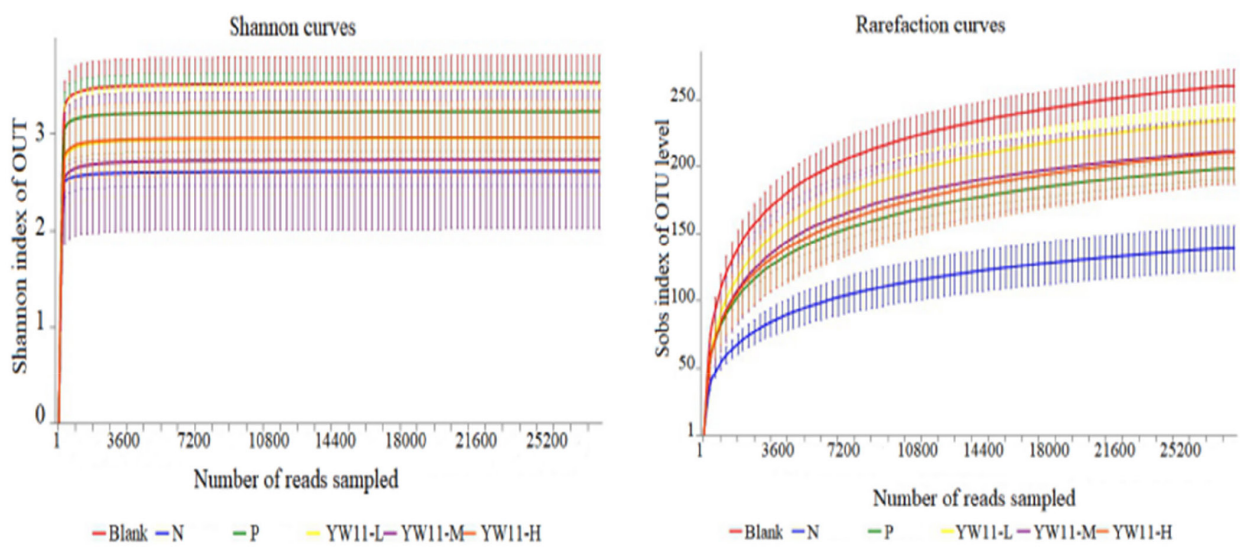

Figure 4. Rarefaction curves for each group calculated at OTU level and at $97 \%$ of sequence similarity clustering. 

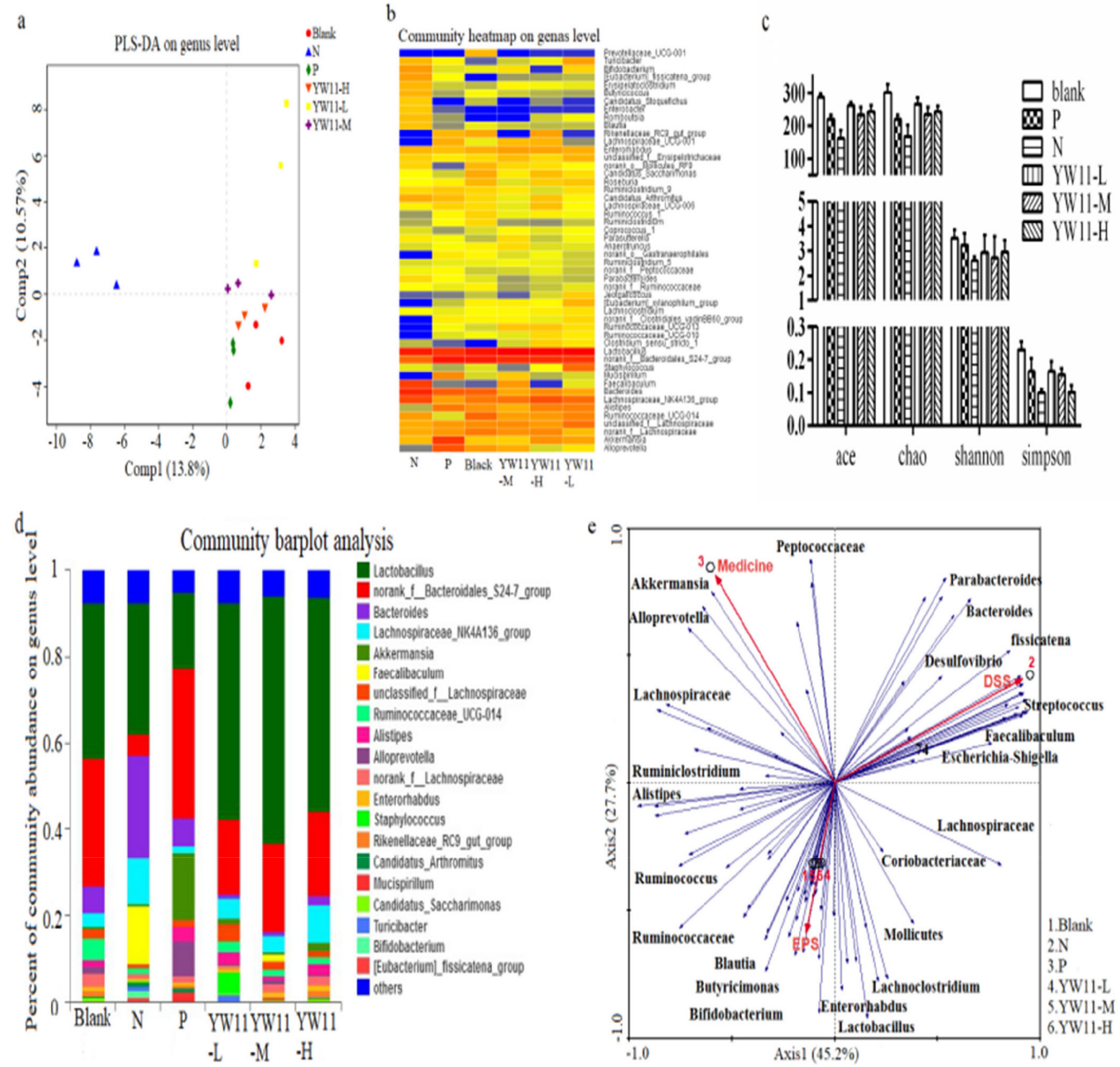

Figure 5. Changes in gut microbiota in a DSS-induced mouse model upon treatment with the EPS produced by L. plantarum YW11. (a) PLS-DA analysis at genus level. (b) Community heatmap at genus level. (c) Diversity index. (d) Community barplot analysis. (e) Distance triplot of the RDA of gut microbiota.

(Chao1 and the abundance-based coverage estimate index) and determination of diversity values (Shannon and Simpson indices). On the basis of qualified sequences reads, the fecal samples from groups B, P, YW11-L, YW11-M, YW11-H were found to have significantly higher diversity values and richness estimates than those from group $\mathrm{N}$, with samples from group $\mathrm{B}$ having the highest values (Fig. 5c).

OTUs analysis of microbiota at genus level showed that a total of 101 bacterial genera were identified in this study (Fig. 5d). The main microbial genera detected in group B were: Lactobacillus (36.1\%), Bacteroidales-S24-7 $(29.7 \%)$, Bacteroides (6.1\%), Ruminococcaceae (4.9\%) and Lachnospiraceae $(3.3 \%)$. Treatment of the mice with DSS decreased the fecal average populations of Lactobacillus, Bacteroidales-S24-7, Ruminococcaceae, as compared with the untreated mice (group B), particularly BacteroidalesS24-7, which decreased more than 5-fold (from 29.7\% to 5.0\%). However, Lachnospiraceae, Faecalibaculum, Fissicatena, escherichia-shigella and Streptococcus increased in the fecal samples from group $\mathrm{N}$ mice. Treatment of the mice with EPS increased the fecal average populations of Lactobacillus, Bacteroidales-S24-7 as compared with the group N mice, but Lachnospiraceae, Faecalibaculum, Fissicatena, Escherichia, Shigella and Streptococcus decreased in the fecal samples from groups YW11-L, YW11-M, YW11-H.

Redundancy analysis (RDA) was performed to identify key phylotypes of the gut microbiota responding to the EPS treatment based on the pyrosequencing data of the fecal samples. The major difference in the gut microbiota composition corresponded to the EPS treatment along the first ordination axis, explaining $45.2 \%$ of the total variability, and the vertical axis explaining $27.7 \%$ of the total variability (Fig. 5e). Analysis by the Monte Carlo permutation procedure showed that the effects of all treatments on the gut microbiota were significant $(P=0.002)$, as indicated by the location of the symbols representing groups B, YW11-L, YW11-M, and YW11$\mathrm{H}$ in the three quadrant, but the symbols of group $\mathrm{N}$ in the first quadrant. Key OTU decreased in IBD mice were recovered by $46.53 \%$ after treatment with the EPS at the medium doses (YW11-M). The samples from the mice treated with medicine (group P) were in the second quadrants, which was different form the effect of EPS.

\section{CONCLUSION}

The EPS produced by L. plantarum YW11 could improve immune response, inhibit colonic inflammation and reduce tissue injury in an IBD mouse model. A middle dose of the EPS (25 mg/ $\mathrm{kg}$ per day) could effectively recover the microbiota diversity and increase the abundance of Roseburia, Ruminococcus and Blautia, correspondingly increasing the content of butyric acid that helped to alleviate systemic inflammation. Besides, administration of the EPS increased the content of antiinflammatory cytokine IL-10 and reduced the content of 
pro-inflammatory cytokines (TNF- $\alpha$, IL- $1 \beta$, IL- 6 , IFN- $\gamma$, IL-12 and IL-18) that relieved enteritis by modulating the immune response. Our results contributed to further understanding of the functional mechanisms of probiotics and probiotic foods.

\section{Conflict of Interest:}

The authors declare that they have no conflict of interest

\section{REFERENCES:}

Amaral FA, Bastos LF, Oliveira TH, Dias AC, Oliveira VL, Tavares LD, Costa VV, Galvão I, Soriani FM, Szymkowski DE, Ryffel B, Souza DG, Teixeira MM (2016) Transmembrane TNF-alpha is sufficient for articular inflammation and hypernociception in a mouse model of gout. Eur J Immunol 46: 204-211. https://doi. org/10.1002/ eji.201545798

Amrouche T, Boutin Y, Prioult G, Fliss I (2006). Effects of bifidobacterial cytoplasm, cell wall and exopolysaccharide on mouse lymphocyte proliferation and cytokine production. Int Dairy J 16: 70-80 https://doi.org/10.1016/j.idairyj.2005.01.008

Backhed F, Manchester JK, Semenkovich CF, Gordon JI (2007) Mechanisms underlying the resistance to diet induced obesity in germfree mice. Proc Natl Acad Sci U S A 104: 979-984. https://doi.org/ $10.1073 /$ pnas.0605374104

Bhat MI, Kumari A, Kapila S, Kapila R (2019) Probiotic lactobacilli mediated changes in global epigenetic signatures of human intestinal epithelial cells during Escherichia coli challenge. Ann Microbiol 69: 603-612. https://doi.org/10.1007/s13213-019-01451-0

Braak CJFT. CANOCO Reference Manual and CanoDraw for Windows User's Guide (2002) Software for Canonical Community Ordination. Version 4.5: Cambridge University Press, Oxford, UK

Bringiotti R, Ierardi E, Lovero R, Losurdo G, Di Leo A, Principi M (2014) Intestinal microbiota: The explosive mixture at the origin of inflammatory bowel disease. World J Gastrointest Pathophysiol 5: 550559. https://doi.org/10.4291/wigp.v5.i4.550

Dasgupta S, Kasper DL (2013) Relevance of commensal microbiota in the treatment and prevention of inflammatory bowel disease. Inflamm Bowel Dis 19: 2478-2489. https://doi.org/10.1097/ MIB.0b013e318297d884

Das D, Baruah R, Goyal A (2014) A food additive with prebiotic properties of an alpha-d-glucan from Lactobacillus plantarum DM5. Int J Biol Macromol 69: 20-26. https://doi.org/10.1016/j.ijbiomac.2014.05.029

Dong L, Wang M, Guo J, Wang J (2019) Role of intestinal microbiota and metabolites in inflammatory bowel disease. Chinese Med J-Peking

Dudik B, Sepova HK, Bilkova A (2018) Inflammatory bowel disease: factors involved in pathogenesis. Ceska Slov Farm 67: 95-100. PMID: 30630325

Gevers D, Kugathasan S, Denson LA, Vázquez-Baeza Y, Van Treuren W, Ren B, Schwager E, Knights D, Song SJ, Yassour M, Morgan XC, Kostic AD, Luo C, González A, McDonald D, Haberman Y, Walters T, Baker S, Rosh J, Stephens M, Heyman M, Markowitz J, Baldassano R, Griffiths A, Sylvester F, Mack D, Kim S, Crandall W, Hyams J, Huttenhower C, Knight R, Xavier RJ (2014) The treatment-naive microbiome in new-onset Crohn's disease. Cell Host Microbe 15: 382-392. https://doi.org/10.1016/j.chom.2014.02.005

Gibson GR, Probert HM, Loo JV, Rastall RA, Roberfroid MB (2004) Dietary modulation of the human colonic microbiota: updating the concept of prebiotics. Nutr Res 17: 259-275. https://doi. org/10.1079/NRR200479

Guarner F (2007) Prebiotics in inflammatory bowel diseases. Br J Nutr 981: S85-S89. https://doi.org/10.1017/S0007114507832958

Hansen J, Gulati A, Sartor RB (2010) The role of mucosal immunity and host genetics in defining intestinal commensal bacteria. Curr Opin Gastroenterol 26: 564-571. https://doi.org/10.1097/ mog.0b013e32833f1195

Kang H, Choi HS, Kim JE, Han NS (2011) Exopolysaccharide-overproducing Lactobacillus paracasei KB28 induces cytokines in mouse peritoneal macrophages via modulation of NF-kappaB and MAPKs. J Microbiol Biotechn 21: 1174-1178. https://doi.org/10.4014/ jmb.1105.05026

Horino J, Fujimoto M, Terabe F, Serada S, Takahashi T, Soma Y, Tanaka K, Chinen T, Yoshimura A, Nomura S, Kawase I, Hayashi N, Kishimoto T, Naka T (2008) Suppressor of cytokine signaling-1 ameliorates dextran sulfate sodium-induced colitis in mice. Int Immunol 20: 753-762. https://doi.org/10.1093/intimm/dxn033

Ishiguro Y (1999) Mucosal proinflammatory cytokine production correlates with endoscopic activity of ulcerative colitis. $J$ Gastroenterol 34: 66-74. https://doi.org/10.1007/s005350050218
Jian Z, Xiao Z, Yunyun J, Wen Z, Ting G, Yongqiang C, Junwei T, Xiaona H, Juan Z, Zhennai Y (2017b) Antioxidant status and gut microbiota change in an aging mouse model as influenced by exopolysaccharide produced by Lactobacillus plantarum YW11 isolated from Tibetan kefir. J Dairy Sci 100: 6025-6041. https://doi. org/10.3168/jds.2016-12480

Kanauchi O, Mitsuyama K, Araki Y, Andoh A (2003) Modification of intestinal flora in the treatment of inflammatory bowel disease. Curr Pharm Design 9: 333-346. https://doi. org/10.2174/1381612033391883

Kim Y, Lim HJ, Jang H, Lee S, Jung K, Lee SW, Lee S, Rho M (2018) Portulaca oleracea extracts and their active compounds ameliorate inflammatory bowel diseases in vitro and in vivo by modulating TNFalpha, IL-6 and IL-1 beta signalling. Food Res Int 106: 335-343. https://doi.org/10.1016/j.foodres.2017.12.058

Kong J, Zhang Z, Musch MW, Ning G, Sun J, Hart J, Bissonnette M, Li YC (2008) Novel role of the vitamin D receptor in maintaining the integrity of the intestinal mucosal barrier. Am J Physiol Gastrointest Liver Physiol 294: G208-G216. https://doi.org/10.1152/ ajpgi.00398.2007

Lee DK, Jang S, Kim MJ, Kim JH, Chung MJ, Kim KJ, Ha NJ (2008) Anti-proliferative effects of Bifidobacterium adolescentis SPM0212 extract on human colon cancer cell lines. BMC Cancer 8. https://doi. org/10.1186/1471-2407-8-310

Lee KH, Park M, Ji KY, Lee HY, Jang JH, Yoon IJ, Oh SS, Kim SM, Jeong YH, Yun CH, Kim MK, Lee IY, Choi HR, Ko KS, Kang HS (2014) Bacterial beta-(1,3)-glucan prevents DSS-induced IBD by restoring the reduced population of regulatory $\mathrm{T}$ cells. Immunobiology 219: 802-812, https://doi.org/10.1016/S2468-1253(17)30247-9

Matsui K, Tsutsui H, Nakanishi K (2003) Pathophysiological roles for IL-18 in inflammatory arthritis. Expert Opin Ther Tar 7: 701-724. https://doi.org/10.1517/14728222.7.6.701

Winderman R, Rabinowitz SS, Vaidy K, Schwarz SM (2019) Measurement of microvascular function in pediatric inflammatory bowel disease. I Pediatr Gastroenterol Nutr 68: 608-609. https://doi.org/ 10.1097/MPG.0000000000002299

Paquola A, Mane N, Cecilia M, Giron, M. Jimenez (2019) Diadenosine tetraphosphate activates P2Y (1) receptors that cause smooth muscle relaxation in the mouse colon. Eur J Pharmacol 855: 160-166. https://doi.org/10.1016/j.ejphar.2019.05.013

Pereira Lde P, Mota MR, Brizeno LA, Nogueira FC, Ferreira EG, Pereira MG, Assreuy AM (2016) Modulator effect of a polysaccharide-rich extract from Caesalpinia ferrea stem barks in rat cutaneous wound healing: Role of TNF-alpha, IL-1 beta, NO, TGFbeta. J Ethnopharmacol 187: 213-223. https://doi.org/10.1016/j. jep.2016.04.043

Pokusaeva K, Fitzgerald GF, van Sinderen D (2011) Carbohydrate metabolism in Bifidobacteria. Genes Nutr 6: 285-306. https://doi.org/ 10.1007/s12263-010-0206-6

Qin J, Li R, Raes J, Arumugam M, Burgdorf KS, Manichanh C, Nielsen T, Pons N, Levenez F, Yamada T, Mende DR, Li J, Xu J, Li S, Li D, Cao J, Wang B, Liang H, Zheng H, Xie Y, Tap J, Lepage P, Bertalan M, Batto JM, Hansen T, Le Paslier D, Linneberg A, Nielsen HB, Pelletier E, Renault P, Sicheritz-Ponten T, Turner K, Zhu H, Yu C, Li S, Jian M, Zhou Y, Li Y, Zhang X, Li S, Qin N, Yang H, Wang J, Brunak S, Doré J, Guarner F, Kristiansen K, Pedersen O, Parkhill J, Weissenbach J; MetaHIT Consortium, Bork P, Ehrlich SD, Wang J (2010) A human gut microbial gene catalogue established by metagenomic sequencing. Nature 464: 59-65. https:// doi.org/10.1038/nature08821

Ramchandran, Shah NP (2009) Effect of exopolysaccharides on the proteolytic and Angiotensin-I converting enzyme-inhibitory activities and textural and rheological properties of low-fat yogurt during refrigerated storage. J Dairy Sci 92: 895-906. https://doi.org/10.1051/ dst/2009039

Sengul N, Isik S, Aslim B, Ucar G, Demirbag AE (2011) The effect of exopolysaccharide-producing probiotic strains on gut oxidative damage in experimental colitis. Digest Dis Sci 56: 707-714. https://doi. org/10.1007/s10620-010-1362-7

Shixiang Z, Limeng Z, Song Q, Lili L (2018) Effect of lactulose intervention on gut microbiota and short chain fatty acid composition of C57BL/6J mice. Microbiology Open 7: 612-612. https://doi. org/10.1002/mbo3.612

Smith PM, Howitt MR, Panikov N, Michaud M, Gallini CA, BohloolyY M, Glickman JN, Garrett WS (2013) The microbial metabolites, short-chain fatty acids, regulate colonic T-reg cell homeostasis. Science 341: 569-573. https://doi.org/10.1126/science.1241165

Sokol H, Pigneur B, Watterlot L, Lakhdari O, Bermúdez-Humarán LG (2008) Faecalibacterium prausnitzii is an anti-inflammatory commensal bacterium identified by gut microbiota analysis of Crohn disease patients. Proc Natl Acad Sci U S A 105: 16731-16736. https://doi. org/10.1073/pnas.0804812105

Staples KJ, Bergmann M, Barnes PJ, Newton R (2000) Stimulus-specific inhibition of IL-5 by cAMP-elevating agents and IL-10 reveals differential mechanisms of action. Biochem Biophys Res Commun 273: $811-815$ 
Sun Q, Luan L, Arif M, Li J, Dong Q, Gao Y, Chi Z, Liu C (2018) Redox-sensitive nanoparticles based on 4-aminothiophenol-carboxymethyl inulin conjugate for budesonide delivery in inflammatory bowel diseases. Carbohydr Polym 189: 352-359. https://doi. org/10.1016/i.carbpol.2017.12.021

Thakur BK, Saha P, Banik G, Saha DR, Grover S, Batish VK, Das S (2016) Live and heat-killed probiotic Lactobacillus casei Lbs2 protects from experimental colitis through Toll-like receptor 2-dependent induction of T-regulatory response. Int Immunopharmacol 36: 39-50. https://doi.org/10.1016/j.intimp.2016.03.033

Luc De Vuyst, Filip De Vin, Frederik Vaningelgem, Bart Degeest (2001) Recent developments in the biosynthesis and applications of heteropolysaccharides from lactic acid bacteria. Int Dairy J 11: 687707. https://doi.org/10.1016/S0958-6946(01)00114-5

Wang J, Wu T, Fang X, Min W, Yang Z (2018) Characterization and immunomodulatory activity of an exopolysaccharide produced by Lactobacillus plantarum JLK0142 isolated from fermented dairy tofu. Int J Biol Macromol 115: 985-993. https://doi.org/10.1016/j. ijbiomac.2018.04.099

Wang J, Zhao X, Tian Z, Yang Y, Yang Z (2015) Characterization of an exopolysaccharide produced by Lactobacillus plantarum YW11 isolated from Tibet Kefir. Carbohyd Polym 125: 16-25. https://doi. org/10.1016/j.carbpol.2015.03.003

Weber B, Saurer L, Mueller C (2009) Intestinal macrophages: differentiation and involvement in intestinal immunopathologies. Semin Immunol 31: 171-184. https://doi.org/10.1007/s00281-009-0156-5

Yan Y, Kolachala V, Dalmasso G, Nguyen H, Laroui H, Sitaraman SV, Merlin D (2009) Temporal and spatial analysis of clinical and molecular parameters in dextran sodium sulfate induced colitis. Plos One 4. https://doi.org/10.1371/journal.pone.0006073

Yan Z, Zheng R, Xiaoli Z, Xiaoliu H, Hua L, Ling W, Cui Z, Zeyuan, Guovao W, Yulong Y (2015) Lactosucrose attenuates intestinal inflammation by promoting Th2 cytokine production and enhancing CD86 expression in colitic rats. Biosci Biotech Bioch 79: 643-651. https://doi.org/10.1080/09168451.2014.991680

Yu R, Zuo F, Ma H, Chen S (2019) Exopolysaccharide-producing bifidobacterium adolescentis strains with similar adhesion property induce differential regulation of inflammatory immune response in Treg/Th17 Axis of DSS-Colitis Mice. Nutrients 11. https://doi. org/10.3390/nu11040782 